\title{
MHD Stagnation Point Flow of a Casson Fluid over a Nonlinearly Stretching Sheet with Viscous Dissipation
}

\author{
Monica Medikare1, Sucharitha Joga1, Kishore Kumar Chidem² \\ ${ }^{1}$ Department of Mathematics, Osmania University, Hyderabad, India \\ ${ }^{2}$ Department of Mathematics, Nizam College, Osmania University, Hyderabad, India \\ Email:monica.medikare@gmail.com,sucharithajoga@gmail.com,kishoresai09@gmail.com
}

Received 6 February 2016; accepted 27 March 2016; published 30 March 2016

Copyright (C) 2016 by authors and Scientific Research Publishing Inc.

This work is licensed under the Creative Commons Attribution International License (CC BY). http://creativecommons.org/licenses/by/4.0/

cc) (i) Open Access

\begin{abstract}
Study to analyze the MHD stagnation point flow of a Casson fluid over a nonlinearly stretching sheet with viscous dissipation was carried out. The partial differential equations governing this phenomenon were transformed into coupled nonlinear ordinary differential equations with suitable similarity transformations. These equations were then solved by finite difference technique known as Keller Box method. The various parameters such as Prandtl number (Pr), Eckert number $(E c)$, Magnetic parameter $(M)$, Casson parameter $(\beta)$ and non linear stretching parameter $(n)$ determining the velocity and temperature distributions, the local Skin friction coefficient and the local Nusselt number governing such a flow were also analyzed. On analysis it was found that the Casson fluid parameter $(\beta)$ decreased both the fluid velocity and temperature whereas an increase in $(\beta)$ increased both the heat transfer rate and wall skin-friction coefficient.
\end{abstract}

\section{Keywords}

Stagnation Point, Casson Fluid, MHD, Viscous Dissipation, Nonlinear Stretching Sheet

\section{Introduction}

The study of boundary layer flow over a stretching sheet has been a great challenge for researchers and it has immense applications in various industrial processes such as extraction of polymer sheet, paper production, wire drawing, glass-fiber production etc. The flow of incompressible fluid over a linearly stretching sheet was first investigated by Crane [1]. The Mass Transfer with suction or blowing over a stretching sheet was investigated by Gupta and Gupta [2]. The heat transfer over a stretching sheet of a hydromagnetic flow has been studied by 
Chakrabarthi and Gupta [3]. The flow over a stretching surface in three diemsional was discussed by Wang [4]. The MHD flow characteristics over a stretching sheet of a viscoelastic fluid was demonstrated by Andersson [5]. Later his work was extended by M. I. Char [6] with mass transfer.

The numerical analysis of magnetic field on Eyring-Powell fluid flow towards a stretching sheet has been discussed by N S Akbar [7].

All the above investigations are restricted for the flow over a linearly stretching sheet but it is not necessary that the stretching sheet has to be linear. Vajravelu [8] analyzed the viscous flow over a nonlinearly stretching sheet. The heat transfer characteristics of a viscous fluid over a non linear stretching sheet was later introduced by Cortell [9]. A great number of studies for the boundary layer flow over a non linear stretching sheet under different aspects of heat and mass transfer, slip and convective boundary conditions etc., are presented in the literature [10]-[16].

The study of stagnation point flow towards a stationary semi infinite wall was first introduced by Hiemenz [17] in a two dimensional case. In his work he reduced the Navier-Stokes equations into non linear ordinary differential equations with the help of similarity transformations. The same problem was extended by Homann [18]. Chiam [19] combined the works of Hiemenz and Crane i.e., the stagnation point flow towards a stretching sheet when the stretching rate of the plate is equal to the strain rate of the stagnation point flow and he found no boundary layer structure near the plate. El-Dab [20] obtained numerical solution of MHD flow of micropolar fluid with heat and mass transfer towards a stagnation point on a vertical plate.

In all these attempts, stagnation point flow due to the stretching sheet was analyzed. The boundary layer flow over a shrinking sheet was first investigated by Wang [21]. He dealt with stagnation point flow on a two dimensional shrinking sheet and axi symmetric stagnation point flow on a axisymmetric shrinking sheet. In contrast, Lok et al. [22] numerically studied non orthogonal stagnation point flow towards a stretching sheet. In his work, he determined that the obliqueness of a free stream line causes the shifting of the stagnation point towards the incoming flow.

Many fluids in industries resemble non-Newtonian behaviour. Non-Newtonian fluids are more appropriate than Newtonian fluids because of their varied industrial applications like petroleum drilling, polymer engineering, certain separation processes, food manufacturing etc.

For non-Newtonian fluids, the relationship between stress and the rate of strain is not linear and it is difficult to express all these properties in a single constitutive equation. Consequently, these fluid models [23]-[31] have been proposed depending on various physical characters.

Casson fluid is one such type of such non-Newtonian fluid, which behaves like an elastic solid, with a yield shear stress existing in the constitutive equation. This fluid model has its origin in modelling of flow of many biological fluids especially blood. Examples of such fluids include foams, yoghurt, molten chocolate, cosmetics, nail polish, tomato puree etc. Casson [32] introduced this model to predict the flow behaviour of pigment oil suspensions of the printing ink type. Later on, several researchers studied Casson fluid pertaining to different flow situations. The unsteady boundary layer flow and heat transfer of a Casson fluid over a moving flat plate with a parallel free stream was studied by Mustafa et al. [33]. The exact solution for boundary layer flow of Casson fluid over a permeable stretching/shrinking sheet with and without external magnetic field was discussed by Bhattacharyya et al. [34] [35]. The Casson fluid has an infinite viscosity at zero rate of shear and a yield stress below which no flow occurs and a zero velocity at an infinite shear rate [36] [37]. An excellent collection of articles can be found in [38]-[40].

Motivated by the above investigations on non-Newtonian fluids and its wide applications, the objective of the present study is to analyze MHD stagnation point flow of a Casson fluid over a non linear stretching sheet with viscous dissipation. We have extended the works of Vajravelu [8] by considering magnetic field, stagnation point and viscous dissipation effects to the flow regime for more physical implications. In addition to this, the roles of the other parameters are explained in brief. The results are displayed in figures and tables. A parametric study of the physical parameters is conducted and a representative set of numerical results for the velocity and temperature profiles as well as the skin friction coefficient and local Nusselt number is illustrated graphically to show interesting features of the solutions. Here the governing partial differential equations were transformed into coupled non linear ordinary differential equations using appropriate similarity tranformations. The transformed ODE's were then solved by Keller Box method. However, to the best of our knowledge no work has been carried out yet to analyze the present result. The layout of this paper is as follows.

In Section 2 the problem is formulated and similarity transformation has been employed to transform the par- 
tial differential equation into a non linear ordinary differential equations. In Section 3 a numerical solution using Keller box method has been discussed. In Section 4 the numerical results have been discussed graphically. Finally, the main concluding observations are mentioned in Section 5.

\section{Mathematical Formulation}

Consider the steady two-dimensional stagnation point flow of an incompressible Casson fluid located at $y=0$. The flow being confined in the region $y>0$. We take the non-linear stretching sheet in the XOY plane (see Figure 1). Along the $x$-axis, two equal and opposite forces are being applied. The surface is stretched in the $x$-direction such that the $x$-component of the velocity varies non-linearly along it, i.e. $U_{w}(x)=c x^{n}$ where $c>0$ is constant of proportionality and $n$ is a power index. A magnetic field of uniform strength $B_{0}$ is applied perpendicular to the surface. The magnetic Reynolds number is taken to be small enough so that the induced magnetic field can be neglected in comparison to the applied magnetic field. It is also assumed that the ambient fluid is moved with a velocity $U_{\infty}(x)=a x^{n}$, where $a>0$ is a constant. The rheological equation of state for an isotropic and incompressible flow of the Casson fluid [Nakamura and Sawada [34], Mustafa et al. [31] is given by

$$
\tau_{i j}= \begin{cases}2\left(\mu_{B}+p_{y} / \sqrt{2 \pi}\right) e_{i j}, & \pi>\pi_{c} \\ 2\left(\mu_{B}+p_{y} / \sqrt{2 \pi_{c}}\right) e_{i j}, & \pi<\pi_{c}\end{cases}
$$

where $\mu_{B}$ and $p_{y}$ are the plastic dynamic viscosity, yield stress of the fluid respectively. Similarly $\pi$ is the product of the component of deformation rate with itself, $\pi=e_{i j} e_{i j}, e_{i j}$ is the $(i, j)$-th component of the deformation rate and $\pi_{c}$ is a critical value of this product based on the non-Newtonian model.

The continuity, momentum and energy equations governing the fluid flow are given by

$$
\begin{gathered}
\frac{\partial u}{\partial x}+\frac{\partial v}{\partial y}=0 \\
u \frac{\partial u}{\partial x}+v \frac{\partial u}{\partial y}=v\left(1+\frac{1}{\beta}\right) \frac{\partial^{2} u}{\partial y^{2}}+U_{\infty} \frac{\partial U_{\infty}}{\partial x}-\frac{\sigma B^{2}(x)}{\rho}\left(u-U_{\infty}\right) \\
u \frac{\partial T}{\partial x}+v \frac{\partial T}{\partial y}=\frac{\kappa}{\rho C_{p}} \frac{\partial^{2} T}{\partial y^{2}}+\left(1+\frac{1}{\beta}\right) \frac{v}{C_{p}}\left(\frac{\partial u}{\partial y}\right)^{2}
\end{gathered}
$$

where $u, v$ are the velocity components in $x, y$ direction respectively, $v$ is the kinematic viscosity, $\rho$ is the viscosity, $\beta=\mu_{B} \sqrt{2 \pi_{c}} / p_{y}$ is the Casson fluid parameter, $\kappa$ is the thermal diffusivity of the fluid, $C_{p}$ is the specific heat and $B=B_{0} x^{\frac{n-1}{2}}$ is the magnetic field.

The suitable boundary conditions are given by

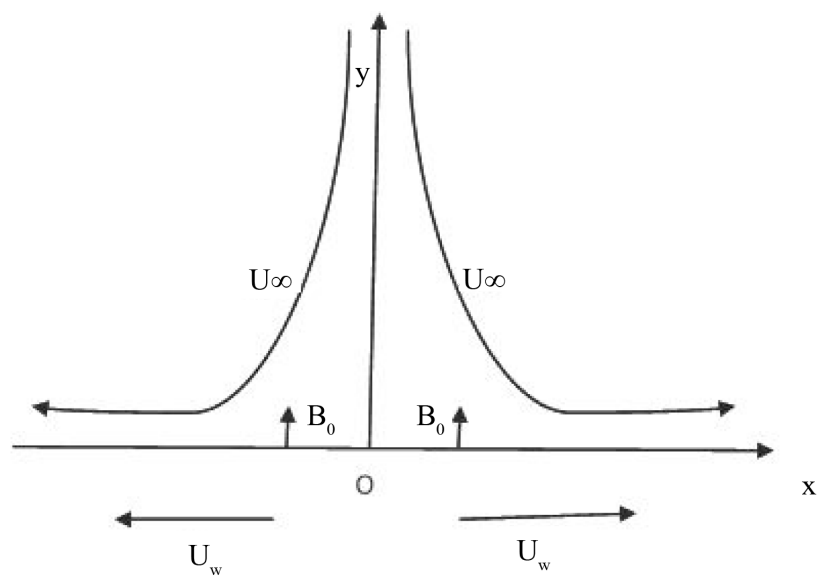

Figure 1. Physical sketch of the given problem. 


$$
\begin{aligned}
& u=U_{w}=c x^{n}, v=0, T=T_{w}, \text { at } y=0 \\
& u \rightarrow U_{\infty}, T \rightarrow T_{\infty} \text { at } y \rightarrow \infty
\end{aligned}
$$

Here, $c(c>0)$ is the surface stretching sheet related parameter. $T_{w}, T_{\infty}$ are the uniform temperature at the sheet, free stream temperature respectively and $n$ is the power index related to the surface stretching speed.

With the help of following similarity transformations

$$
\begin{gathered}
u=c x^{n} f^{\prime}(\eta), v=\sqrt{c v \frac{(n+1)}{2} x^{\frac{n-1}{2}}}\left[f(\eta)+\frac{n-1}{n+1} \eta f^{\prime}(\eta)\right], \\
\theta(\eta)=\frac{T-T_{\infty}}{T_{w}-T_{\infty}}, \quad \eta=y \sqrt{\frac{c(n+1)}{2 v}} x^{\frac{n-1}{2}}
\end{gathered}
$$

The Equations (1), (2) and (3) are transformed into coupled non linear ordinary differential equations as follows.

$$
\begin{gathered}
\left(1+\frac{1}{\beta}\right) f^{\prime \prime \prime}+f f^{\prime \prime}-\frac{2 n}{n+1}\left(f^{\prime 2}-\lambda^{2}\right)+M\left(\lambda-f^{\prime}\right)=0 \\
\theta^{\prime \prime}+\operatorname{Prf} \theta^{\prime}+\left(1+\frac{1}{\beta}\right) \operatorname{Pr} \cdot E c \cdot f^{\prime \prime 2}=0
\end{gathered}
$$

and the boundary conditions are transformed into

$$
\begin{gathered}
f^{\prime}(\eta)=1, \quad f(\eta)=0, \theta(\eta)=1 \text { at } \eta=0 \\
f^{\prime}(\eta) \rightarrow \lambda, \theta(\eta) \rightarrow 0 \text { at } \eta=\infty
\end{gathered}
$$

where $\operatorname{Pr}=\frac{\mu C_{p}}{\kappa}$ is the Prandtl Number, $M=\frac{2 \sigma B_{0}^{2}}{\rho c(n+1)}$ is the magnetic parameter,

$$
E c=\frac{U_{w}^{2}}{C_{p}\left(T_{w}-T_{\infty}\right)} \text { is the Eckert number and } \lambda=\frac{a}{c} \text { is the velocity ratio parameter. }
$$

where prime denotes the differentiation with respect to $\eta$.

The quantities of practical interest are the Skin friction coefficient $C_{f}$ and the Local Nusselt number $N u_{x}$ which are defined as

$$
C_{f}=\frac{\tau_{w}}{\rho U_{w}^{2}}, \quad N u_{x}=\frac{x q_{w}}{k\left(T_{w}-T_{\infty}\right)}
$$

where $\tau_{w}$ is the shear stress or skin friction along the stretching sheet and $q_{w}$ is the heat flux from the sheet.

Hence the dimensionless form of Skin friction $C_{f}$ and the Local Nusselt number $N u_{x}$ are given by

$$
C_{f}\left(R e_{x}\right)^{1 / 2}=\left(1+\frac{1}{\beta}\right) f^{\prime \prime}(0), \frac{N u_{x}}{\left(R e_{x}\right)^{1 / 2}}=-\theta^{\prime}(0)
$$

where $R e_{x}=\frac{U_{w} X}{v}$ is the local Reynolds number.

\section{Numerical Solution}

The numerical solution for the above coupled ordinary differential equations for different values of governing parameters is obtained using finite difference scheme called Keller-box method. This method involves the four main steps which are as follows:

1) Reduce the equation or system of equations to a first order system.

2) Write the difference equations using central differences.

3) Linearize the resulting algebraic equations (if they are non-linear) by Newton's method. 
4) Write them in matrix-vector form and use the block-tridiagonal-elimination technique to solve the linear system.

This method has been widely used in laminar and turbulent boundary layer flows. It seems to be much faster, easier to program, more efficient and flexible to use than other methods.

\section{Results and Discussion}

The numerical computations are carried out with the help of Keller box method. The effects of different parameters like Stagnation point, MHD, viscous dissipation on velocity and temperature profiles has been clearly analyzed including with its physical quantities of significance. The effect of Casson fluid parameter on skin friction and local Nusselt number has been examined. Apart from those the various quantities of non linear stretching parameter were also analyzed.

To verify the accuracy of the present results, comparison has been made with the previous results of Vajravelu and Cortell (Table 1).

Table 1 clearly shows the values of skin friction coefficient $f^{\prime \prime}(0)$ and heat transfer rate $\theta^{\prime}(0)$ at the surface for different values of non linear stretching parameter $n$ which are found to be in excellent agreement.

The effects of magnetic parameter $M$ and velocity ratio parameter $\lambda$ on the flow field velocity is displayed in Figure 2. It shows that the velocity of the fluid is not affected by various values of $M$ for $\lambda=1$ i.e., when the velocity of ambient fluid and the velocity of the sheet are same, where as for $\lambda=0.2$ an increase in $M$ decreases the velocity boundary layer thickness. However, with an increase in $M$ the flow field velocity increases and boundary layer thickness decreases for $\lambda=2$. Due to the Lorentz force induced by the action of magnetic field ,the thickness of boundary layer decreases for both $\lambda=0.2$ and $\lambda=2$.

\begin{tabular}{|c|c|c|c|c|c|c|c|}
\hline \multirow{3}{*}{$n$} & \multicolumn{3}{|c|}{ Vajravelu } & \multirow{3}{*}{$\begin{array}{l}\text { Cortell } \\
f^{\prime \prime}(0)\end{array}$} & \multicolumn{3}{|c|}{ Present Study } \\
\hline & \multirow{2}{*}{$\begin{array}{c}f^{\prime \prime}(0) \\
P r\end{array}$} & \multicolumn{2}{|c|}{$\theta^{\prime}(0)$} & & \multirow{2}{*}{$\begin{array}{c}f^{\prime \prime}(0) \\
P r\end{array}$} & \multicolumn{2}{|c|}{$\theta^{\prime}(0)$} \\
\hline & & 0.71 & 7.0 & & & 0.71 & 7.0 \\
\hline 1 & -1.0000 & -0.4590 & -1.8953 & -1.000000 & -1.0000 & -0.4590 & -1.8954 \\
\hline 5 & -0.1945 & -0.4394 & -1.8610 & - & -0.1945 & -0.4395 & -1.8616 \\
\hline 10 & -1.2348 & -0.4357 & -1.8541 & -1.234875 & -1.2348 & -0.4356 & -1.8547 \\
\hline
\end{tabular}

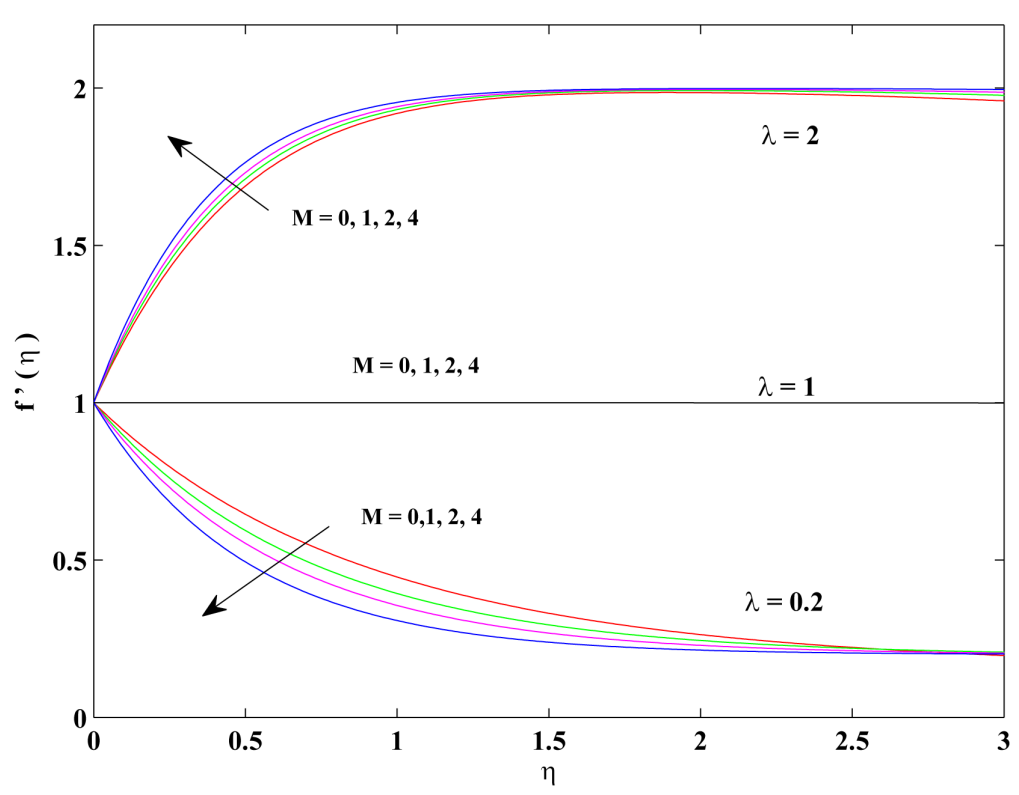

Figure 2. Velocity profile for different values of $M$ when $\lambda=0.2,1,2$ and $\beta=2, n=10, \operatorname{Pr}=0.71$. 
Figure 3 depicts the effect of the velocity ratio parameter on the flow field velocity. It can be observed that for $\lambda<1$ i.e., when the stretching velocity of the sheet exceeds the free stream velocity, the velocity of the fluid and the boundary layer thickness increases with an increase in $\lambda$. Moreover, for $\lambda>1$ i.e., when the free stream exceeds the stretching velocity, the flow velocity increases and the boundary layer thickness decreases with an increase in $\lambda$. If $\lambda=1$ i.e., when the stretching and free stream velocities are equal, then there is no boundary layer of Casson fluid flow near the sheet.

Figure 4 and Figure 5 indicates the effect of Casson parameter $\beta$ on velocity and temperature profiles for a non linear stretching parameter $n=10$. It can be observed from Figure 4 that the fluid velocity decreases when $\beta$ increases. Due to the increase of Casson parameter $\beta$, the yield stress $p_{y}$ reduces and hence the momentum boundary layer thickness decreases.

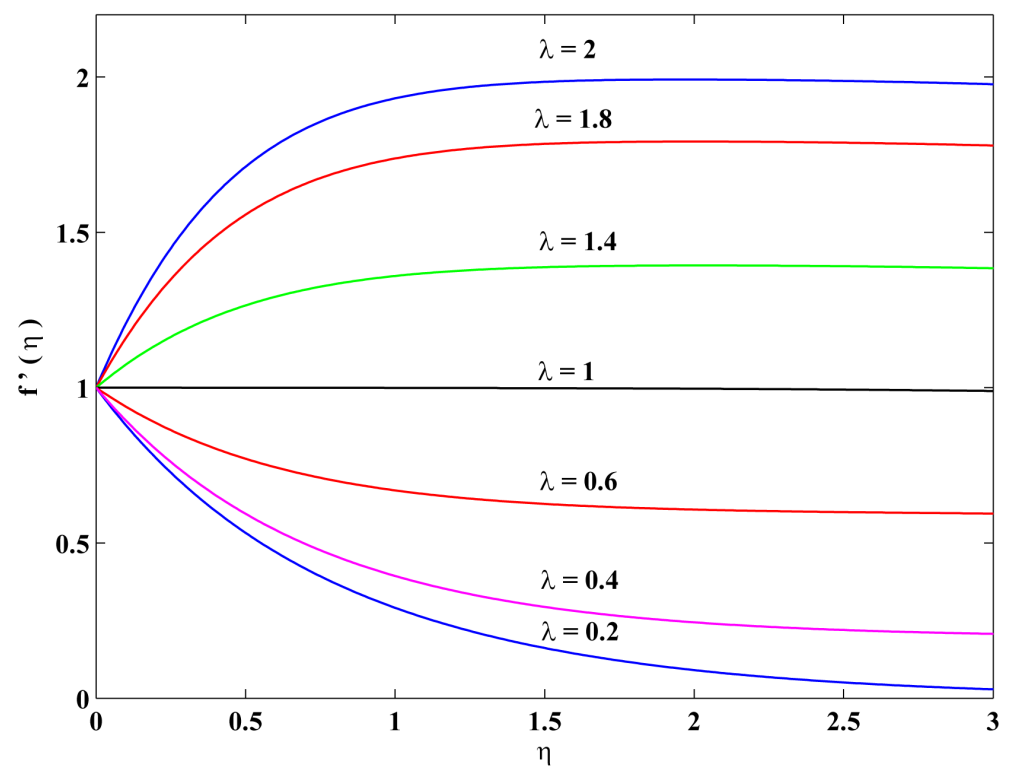

Figure 3. Velocity profile for various values of $\lambda$ when $M=1, \beta=2, n=10, \operatorname{Pr}=$ 0.71 and $E c=1$.

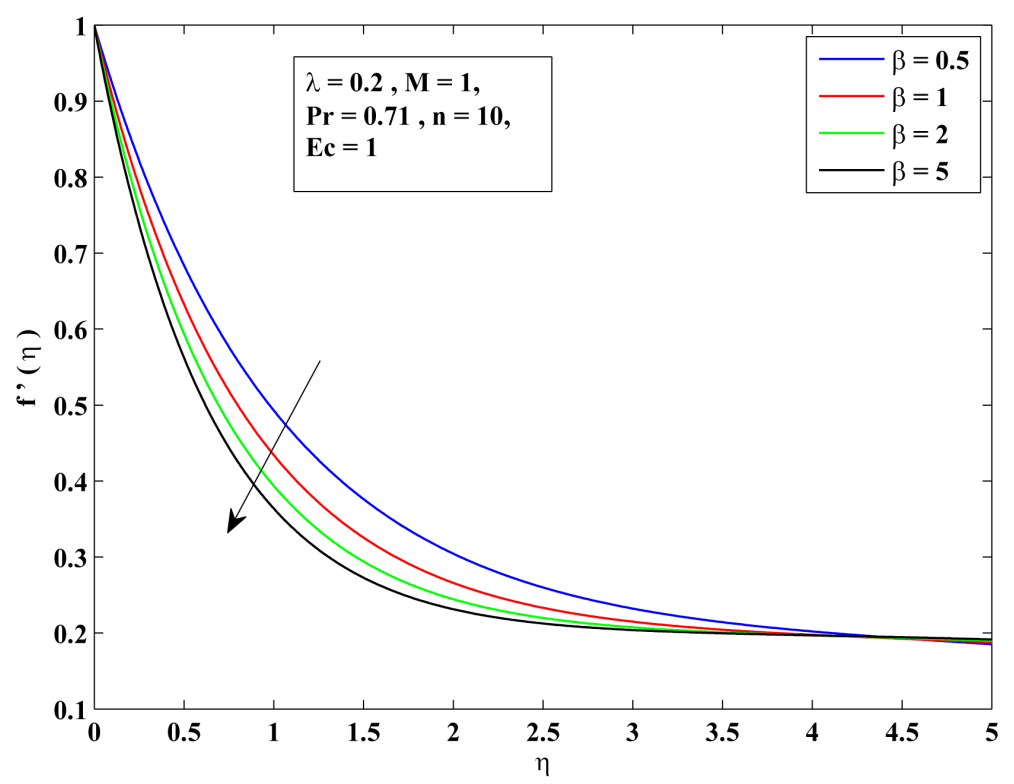

Figure 4. Velocity profile for various values of $\beta$. 
Figure 5 shows that the temperature decreases with increase in $\beta$ implying that the thermal boundary layer decreases. In the vicinity of the sheet the temperature profile curves for larger values of $\beta$ are lower than for those with smaller values of $\beta$. However, as we move far from the sheet within the thermal boundary layer, viscous dissipation vanishes and the curves for larger values of $\beta$ tend to override for smaller values of $\beta$. Hence the temperature profiles intersect each other at a point and the behaviour goes other way round at this point.

Figure 6 and Figure 7 indicates the velocity and the temperature profiles for various values of nonlinear

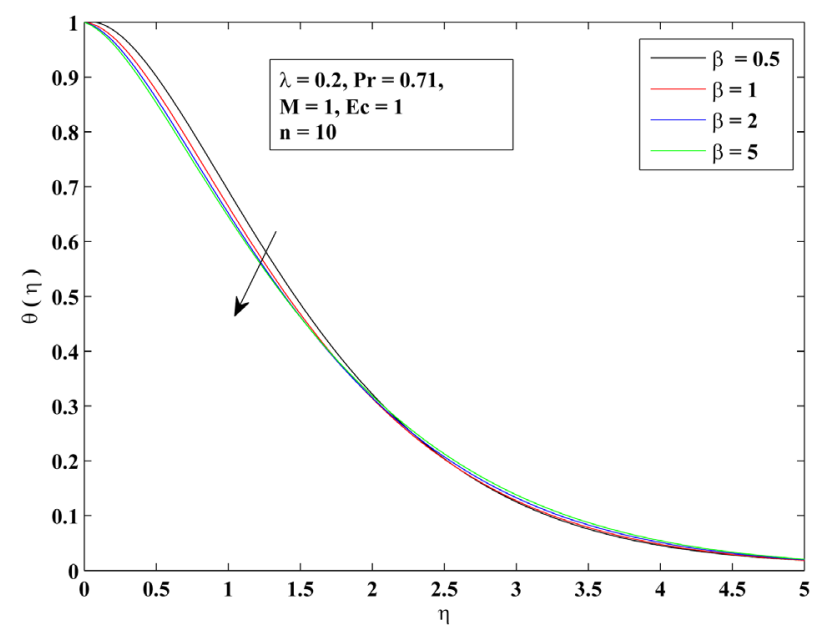

Figure 5. Temperature profile for various values of $\beta$.

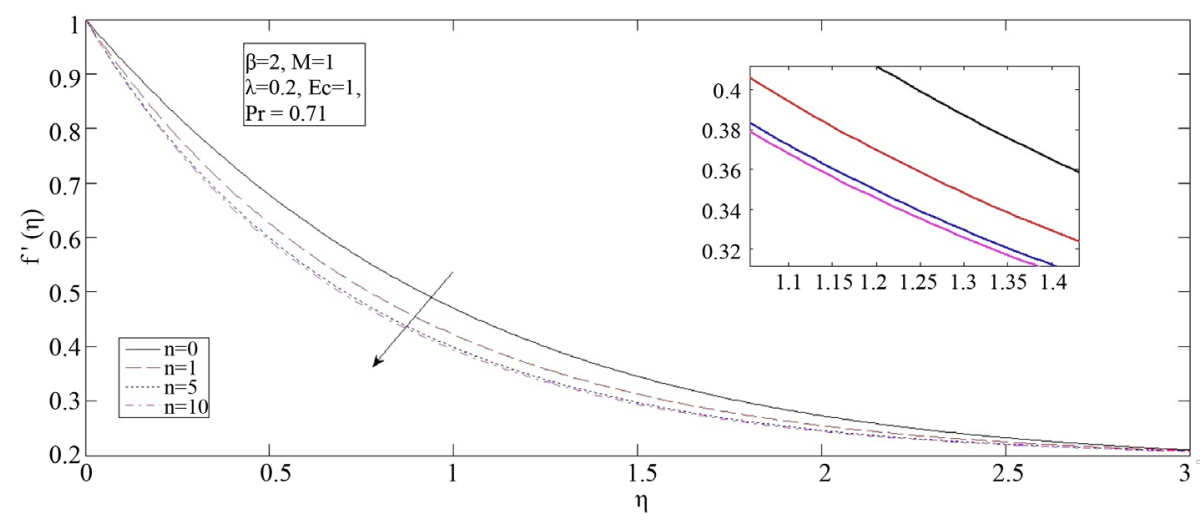

Figure 6. Velocity profile for various values of $n$.

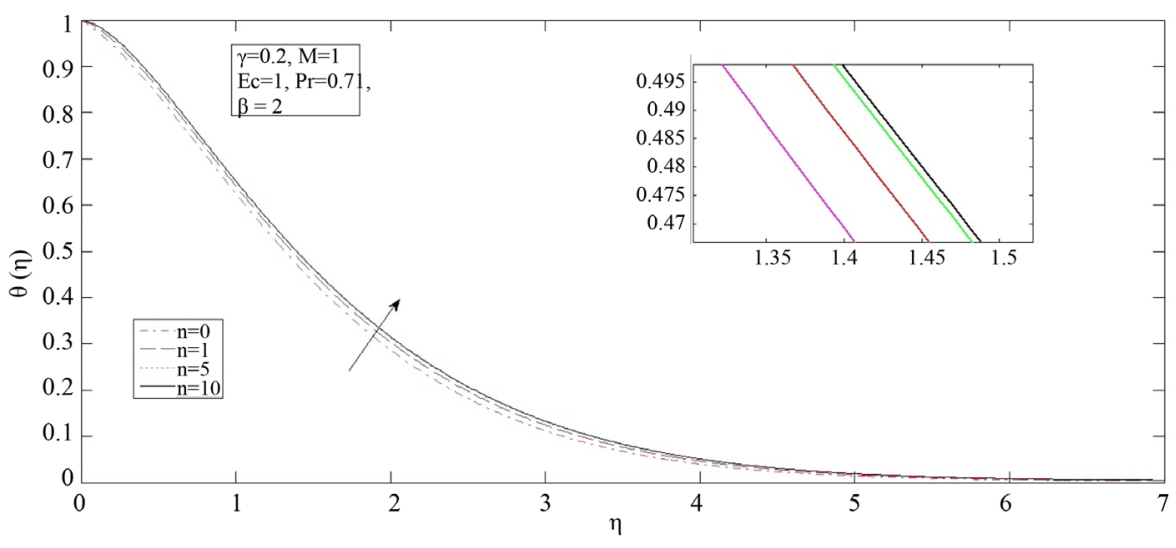

Figure 7. Temperature profile for various values of $n$. 
stretching parameter $n$. Figure 6 shows that the velocity of the fluid decreases with an increase in power index $n$, while the temperature increases (Figure 7). From the above two figures no specific variations were observed when $n$ is large. This is because of the term $\frac{2 n}{n+1}$ which approximately approaches to 2 when $n$ reaches infinity, as mentioned in the subfigures. Therefore the observations for the large values of $n$ is not a study of interest.

Figure 8 indicates the effect of magnetic parameter $M$ on velocity and temperature profiles. The velocity of the fluid decreases with an increase in $M$. This causes retarding effect on the flow field leading to the prominent reduction in velocity due to Lorentz force effect. Therefore, the Lorentz force increases the opposition of the flow of fluid reducing the velocity of the flow.

Figure 9 shows the temperature profile for various values of $\operatorname{Pr}$. It is clear that the dimensionless parameter $\theta$

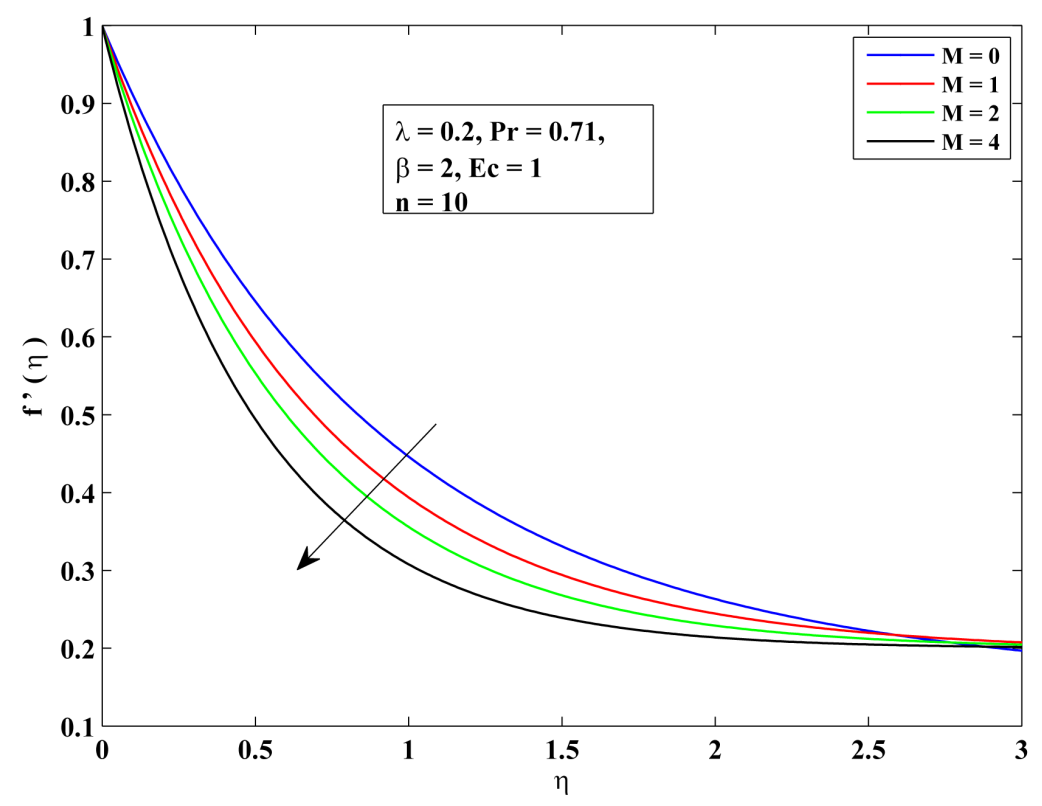

Figure 8. Velocity profile for various values of $M$.

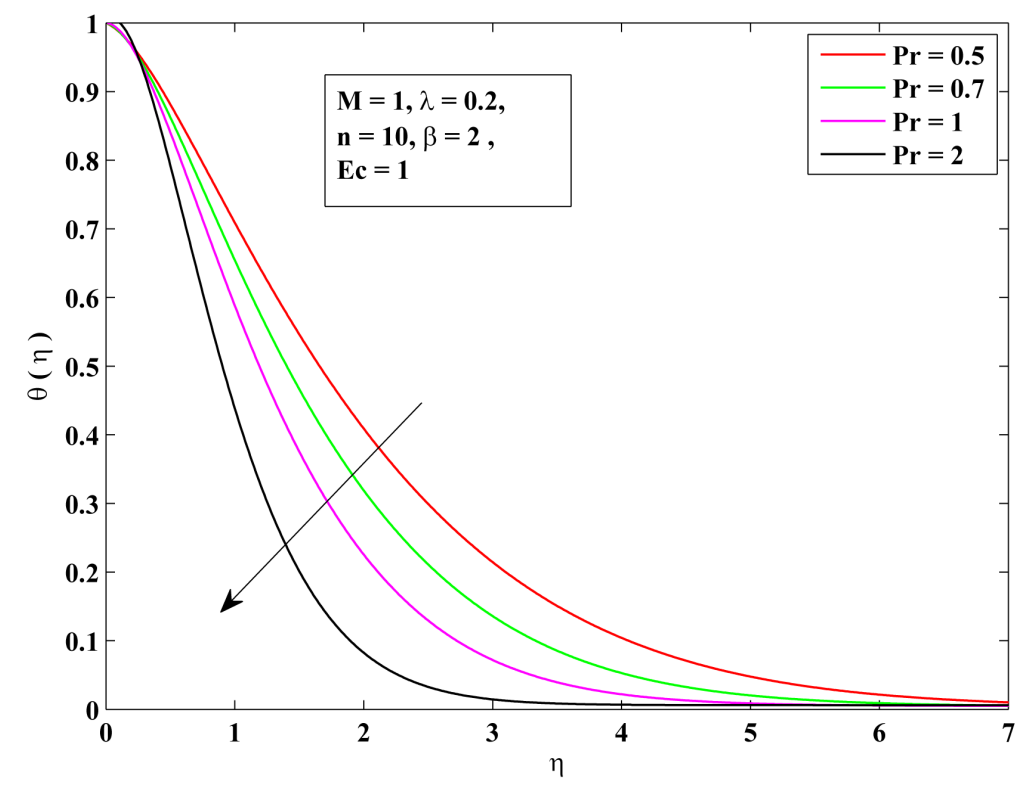

Figure 9. Temperature profile for various values of $\mathrm{Pr}$. 
decreases with the increase in Prandtl number. Since the Prandtl number is the ratio of momentum diffusivity to thermal diffusivity; it reduces the thermal boundary layer thickness. In general the Prandtl number is used in heat transfer problems to reduce the relative thickening of the momentum and the thermal boundary layers.

The influence of Eckert number $E c$ for linearly/non linearly stretching parameters i.e., $n=1, n=10$ is depicted in Figure 10. It illustrates that the temperature increases with an increase in Ec. The increase in temperature profile is higher for non linear stretching parameter than that for linear stretching parameter. The viscous dissipation produces heat due to drag between the fluid particles and this extra heat causes an increase of the initial fluid temperature, and these variations are clearly mentioned for linearly $(n=1)$ and nonlinearly stretching cases $(n=10)$. Both Figure 10 and Figure 11 reveal that the viscous dissipation may not only cause thermal reversal but also increase the thermal boundary layer whether $\lambda \leq 1$ or $\lambda>1$.

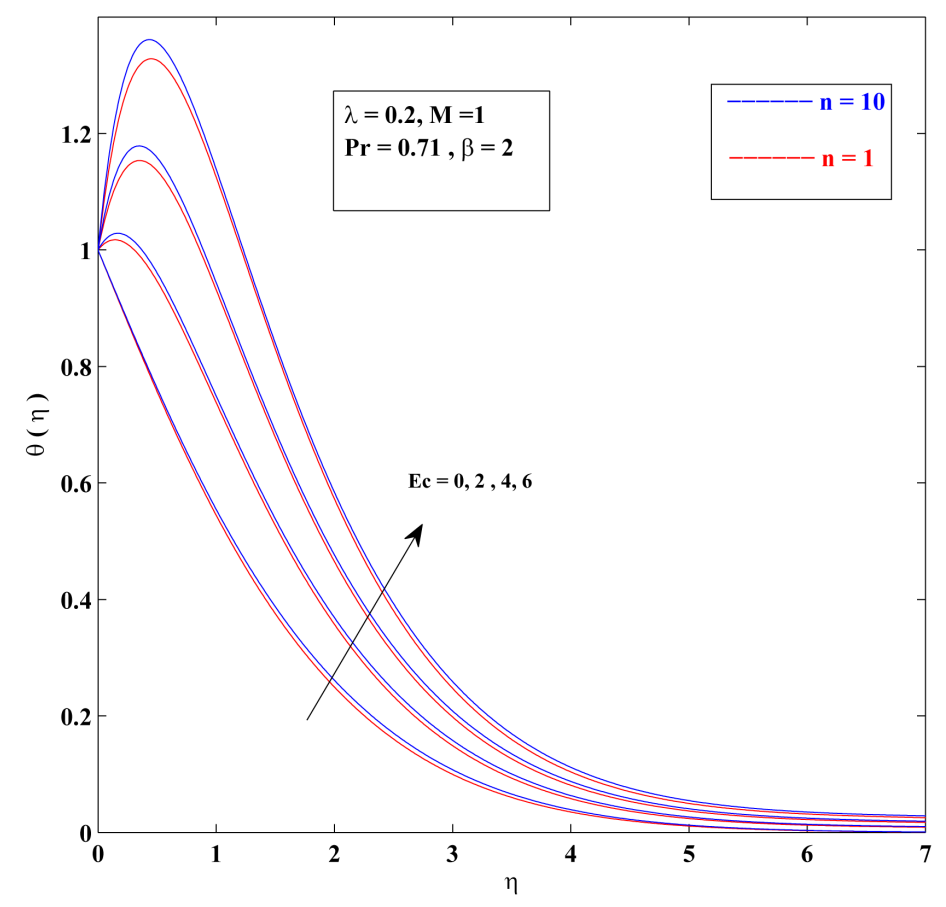

Figure 10. Temperature profile for various values of $E c, \lambda=0.2$.

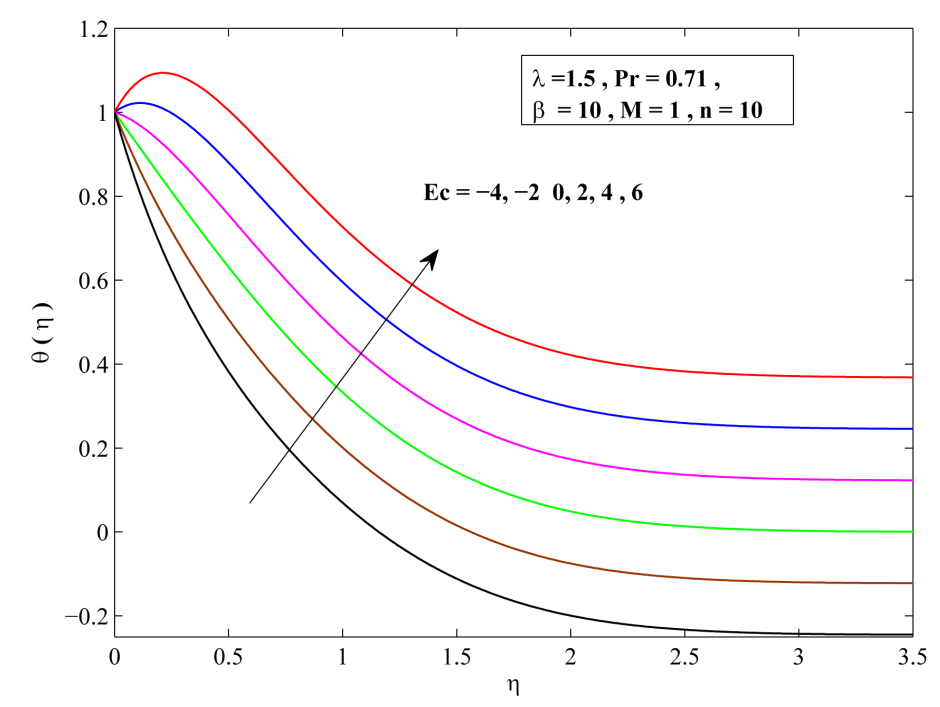

Figure 11. Temperature profile for various values of $E c, \lambda=1.5$. 
Figure 12 and Figure 13 indicates the skin friction coefficient and Local Nusselt number with variations of Casson parameter $\beta$ respectively. Figure 12 depicts the variation of the skin-friction coefficient with $\beta$ for two values of non linear stretching parameter $n=1, n=10$. It is found that as $\beta$ increases the skin-friction coefficient $f^{\prime \prime}(0)$ increases. From this figure, it can be observed that the shear stress at the wall is negative. Physically, a negative sign implies that a drag force has been exerted by the surface on the fluid, and a positive sign implies the opposite.

Figure 13 indicates the variation of heat transfer coefficient $-\theta^{\prime}(0)$ with Casson parameter $\beta$. As $\beta$ increases, the heat transfer coefficient gradually increases. Wall temperature gradient $-\theta^{\prime}(0)$ decreases with increase in $n$.

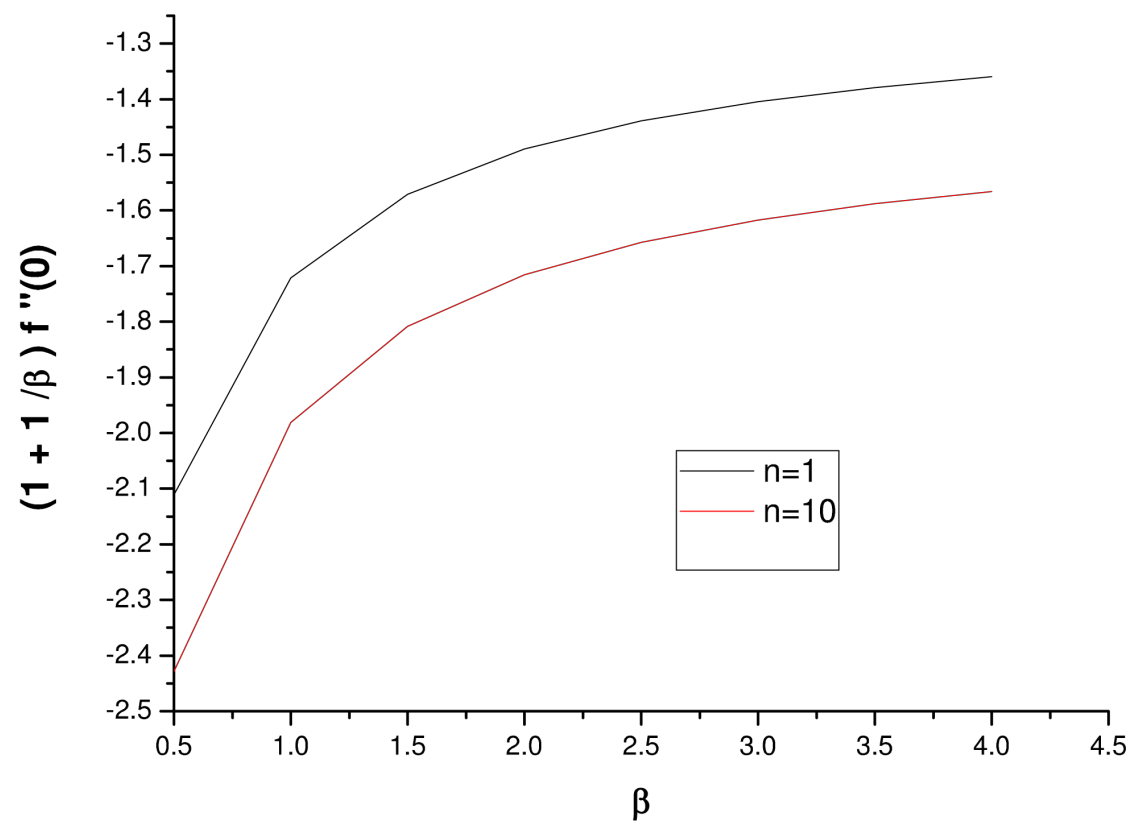

Figure 12. Skin friction coefficient for various values of Casson parameter $\beta$.

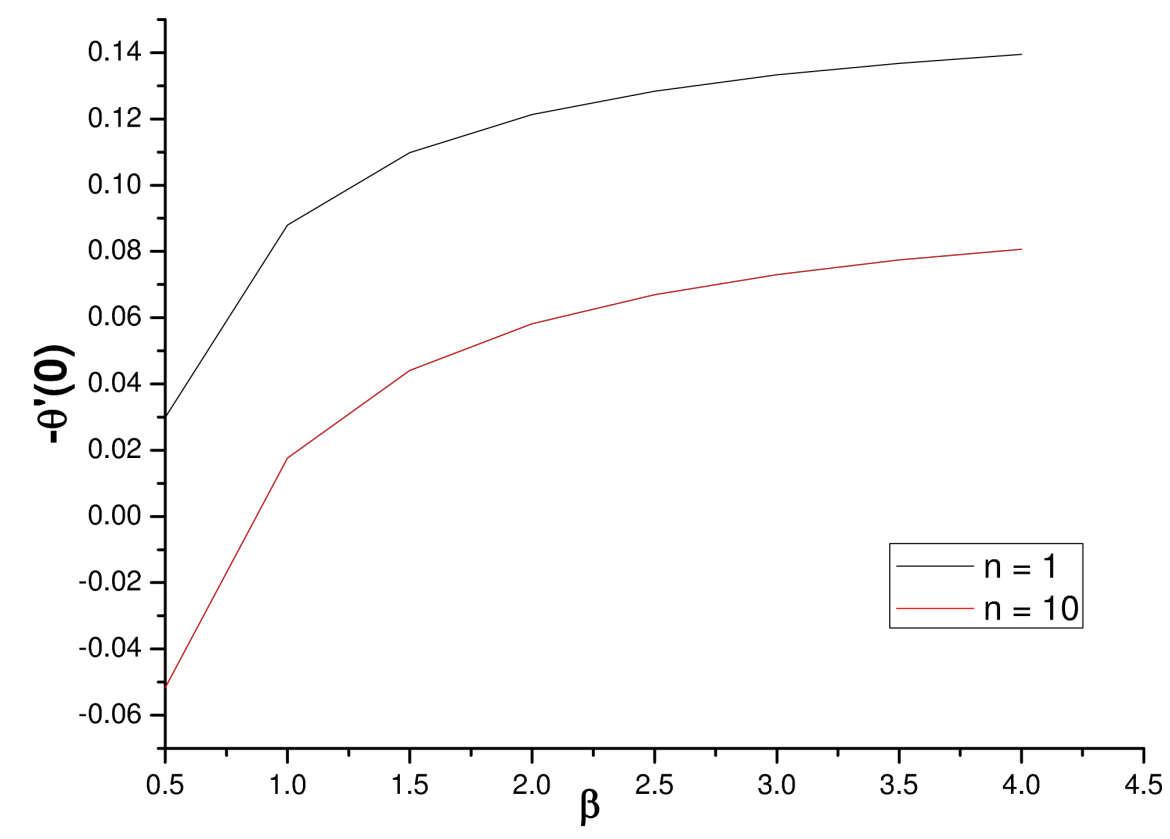

Figure 13. Local Nusselt number for various values of Casson parameter $\beta$. 


\section{Conclusion}

In the present study, MHD stagnation point flow of a Casson fluid over a non linearly stretching sheet are investigated with viscous dissipation. The numerical solution is obtained by Keller box technique. The effects of various governing parameters on heat flow characteristics were analyzed. Briefly the above discussion can be summarized as follows.

- The velocity boundary layer thickness reduces for magnetic parameter $M$.

- An increase in Casson parameter $\beta$ decreases the velocity of the fluid as well as the thermal boundary layer thickness.

- The velocity of the fluid decreases and temperature increases with an increase in nonlinear stretching parameter..

- The Eckert number increases the thermal boundary layer thickness where as the Prandtl number decreases it.

- Both the skin friction coefficient and heat transfer coefficient increases with Casson parameter $\beta$.

\section{References}

[1] Crane, LJ. (1970) Flow Past a Stretching Plate. Zeitschrift für Angewandte Mathematik und Physik, 21, 645-647. http://dx.doi.org/10.1007/BF01587695

[2] Gupta, P.S. and Gupta, A.S. (1977) Heat and Mass Transfer on a Stretching Sheet with Suction or Blowing. The Canadian Journal of Chemical Engineering, 55, 744-746. http://dx.doi.org/10.1002/cjce.5450550619

[3] Chakrabarti, A. and Gupta, A.S. (1979) Hydromagnetic Flow and Heat Transfer over a Stretching Sheet. Quarterly of Applied Mathematics, 37, 73-78.

[4] Wang, C.Y. (1984) The Three Dimensional Flow Due to a Stretching Flat Surface. Physics of Fluids, 27, $1915-1917$. http://dx.doi.org/10.1063/1.864868

[5] Andersson, H.I. (1992) MHD Flow of a Viscoelastic Fluid Past a Stretching Surface. Acta Mechanica, 95, $227-230$. http://dx.doi.org/10.1007/BF01170814

[6] Char, M.I. (1994) Heat and Mass Transfer in a Hydromagnetic Flow of the Viscoelastic Fluid over a Stretching Sheet. Journal of Mathematical Analysis and Applications, 186, 674-689,

[7] Akbar, N.S. and Ebaid, A. (2015) Numerical Analysis of Magnetic Field on Eyring-Powell Fluid Flow towards a Stretching Sheet. Journal of Magnetism and Magnetic Materials, 382, 355-358.

http://dx.doi.org/10.1016/j.jmmm.2015.01.088

[8] Vajravelu, K. (2001) Viscous Flow over a Nonlinearly Stretching Sheet. Applied Mathematics and Computation, 124, 281-288

[9] Cortell, R. (2007) Viscous Flow and Heat Transfer over a Nonlinearly Stretching Sheet. Applied Mathematics and Computation, 184, 864-873. http://dx.doi.org/10.1016/j.amc.2006.06.077

[10] Abbas, Z. and Hayat, T. (2011) Stagnation Slip Flow and Heat Transfer over a Nonlinear Stretching Sheet. Numerical Methods for Partial Differential Equations, 27, 302-314.

[11] Hayat, T., Javed, T. and Abbas, Z. (2009) MHD Flow of a Micropolar Fluid near a Stagnation-Point Towards a Non-Linear Stretching Surface. Nonlinear Analysis: Real World Applications, 10, 1514-1526

[12] Mabood, F., Khan, W.A. and Ismail, A.I.M. (2015) MHD Boundary Layer Flow and Heat Transfer of Nanofluids over a Nonlinear Stretching Sheet: A Numerical Study. Journal of Magnetism and Magnetic Materials, 374, 569-576.

[13] Prasad, K.V., Vajravelu, K. and Dattri, P.S. (2010) Mixed Convection Heat Transfer over a Non-Linear Stretching surface with Variable Fluid Properties. International Journal of Non-Linear Mechanics, 45, 320-330. http://dx.doi.org/10.1016/j.ijnonlinmec.2009.12.003

[14] Rana, P. and Bhargava, R. (2012) Flow and Heat Transfer of a Nanofluid over a Nonlinearly Stretching Sheet: A Numerical Study. Communications in Nonlinear Science and Numerical Simulation, 17, 212-226. http://dx.doi.org/10.1016/j.cnsns.2011.05.009

[15] Ghotbi, A.R. (2009) Homotopy Analysis Method for Solving the MHD flow over a Non-Linear Stretching Sheet. Communications in Nonlinear Science and Numerical Simulation, 14, 2653-2663. http://dx.doi.org/10.1016/j.cnsns.2008.08.006

[16] Fanga, T. (2014) Magneto-Hydrodynamic Viscous Flow over a Nonlinearly Moving Surface: Closed-Form Solutions. The European Physical Journal Plus, 129, 92. http://dx.doi.org/10.1140/epjp/i2014-14092-4

[17] Hiemenz, K. (1911) Die Grenzschicht an einem in den gleichförmigen Flüssigkeitsstrom eingetauchten geraden Kreiszylinder. Dinglers Polytech Journal, 326, 321-410. 
[18] Homann, F. (1936) Der Einfluss grosset Zähigkeit bei der Strömung um den Zylinder and um die Kugel. Zeitschrift für Angewandte Mathematik und Mechanik, 16, 153-164. http://dx.doi.org/10.1002/zamm.19360160304

[19] Chiam, T.C. (1994) Stagnation-Point Flow towards a Stretching Plate. Journal of the Physical Society of Japan, 63, 2443-2444. http://dx.doi.org/10.1143/JPSJ.63.2443

[20] El-Dab, N.T., Ghaly, A.Y., Rizkallah, R.R., Ewis, K.M. and Al-Bareda, A.S. (2015) Numerical Solution of MHD Flow of Micropolar Fluid with Heat and Mass Transfer towards a Stagnation Point on a Vertical Plate. American Journal of Computational Mathematics, 5, 158-174. http://dx.doi.org/10.4236/ajcm.2015.52013

[21] Wang, C.Y. (2008) Stagnation Point Flow towards a Shrinking Sheet. International Journal of Non-Linear Mechanics, 43, 377-382. http://dx.doi.org/10.1016/j.ijnonlinmec.2007.12.021

[22] Lok, Y.Y., Amin, N. and Pop, I. (2006) Non-Orthogonal Stagnation Point Flow towards a Stretching Sheet. International Journal of Non-Linear Mechanics, 41, 622-627. http://dx.doi.org/10.1016/j.ijnonlinmec.2006.03.002

[23] Fox, V.G., Erickson, L.E. and Fan, L.T. (1969) The Laminar Boundary Layer on a Moving Continuous Flat Sheet Immersed in a Non-Newtonian Fluid. AIChE Journal, 15, 327-333. http://dx.doi.org/10.1002/aic.690150307

[24] Wilkinson, W. (1970) The Drainage of a Maxwell Liquid down a Vertical Plate. Chemical Engineering Journal, 1, 255-257. http://dx.doi.org/10.1016/0300-9467(70)80008-9

[25] Djukic, D.S. (1974) Hiemenz Magnetic Flow of Power-Law Fluids. Journal of Applied Mechanics, 41, 822-823. http://dx.doi.org/10.1115/1.3423405

[26] Rajagopal, K.R. (1980) Viscometric Flows of Third Grade Fluids. Mechanics Research Communications, 7, 21-25. http://dx.doi.org/10.1016/0093-6413(80)90020-8

[27] Rajagopal, K.R. and Gupta, A.S. (1981) On a Class of Exact Solutions to the Equations of Motion of a Second Grade Fluid. International Journal of Engineering Science, 19, 1009-1014. http://dx.doi.org/10.1016/0020-7225(81)90135-X

[28] Dorier, C. and Tichy, J. (1992) Behavior of a Bingham-Like Viscous Fluid in Lubrication Flows. Journal of NonNewtonian Fluid Mechanics, 45, 291-310. http://dx.doi.org/10.1016/0377-0257(92)80065-6

[29] Zhou, X.-F. and Gao, L. (2007) Effect of Multipolar Interaction on the Effective Thermal Conductivity of Nanofluids. Chinese Physics B, 16, 2028-2032. http://dx.doi.org/10.1088/1009-1963/16/7/037

[30] Cui, Z.-W., Liu, J.-X., Yao, G.-J. and Wang, K.-X. (2010) Borehole Guided Waves in a Non-Newtonian (Maxwell) Fluid-Saturated Porous Medium. Chinese Physics B, 19, Article ID: 084301. http://dx.doi.org/10.1088/1674-1056/19/8/084301

[31] Bhattacharyya, K. and Layek, G.C. (2011) MHD Boundary Layer Flow of Dilatant Fluid in a Divergent Channel with Suction or Blowing. Chinese Physics Letters, 28, Article ID: 084705. http://dx.doi.org/10.1088/0256-307X/28/8/084705

[32] Casson, N. (1959) A Flow Equation for Pigment Oil Suspensions of the Printing Ink Type. In: Mill, C.C., Ed., Rheology of Disperse Systems, Pergamon Press, Oxford, 84-102.

[33] Mustafa, M., Hayat, T., Pop, I. and Aziz, A. (2011) Unsteady Boundary Layer Flow of a Casson Fluid Due to an Impulsively Started Moving Flat Plate. Heat Transfer, 40, 563-576. http://dx.doi.org/10.1002/htj.20358

[34] Bhattacharyya, K., Hayat, T. and Alsaedi, A. (2014) Exact Solution for Boundary Layer Low of Casson Fluid over a Permeable Stretching/Shrinking Sheet. Zeitschrit fur Angewandte Mathematik und Mechanik, 94, 522-528. http://dx.doi.org/10.1002/zamm.201200031

[35] Bhattacharyya, K., Hayat, T. and Alsaedi, A. (2013) Analytic Solution for Magneto Hydrodynamic Boundary Layer Low of Casson Fluid over a Stretching/Shrinking Sheet with Wall Mass Transfer. Chinese Physics B, 22, Article ID: 024702. http://dx.doi.org/10.1088/1674-1056/22/2/024702

[36] Nakamura, M. and Sawada, T. (1988) Numerical Study on the Flow of a Non-Newtonian Fluid through an Axisymmetric Stenosis. Journal of Biomechanical Engineering, 110, 137-143. http://dx.doi.org/10.1115/1.3108418

[37] Bird, R.B., Dai, G.C. and Yarusso, B.J. (1983) The Rheology and Flow of Viscoplastic Materials. Reviews in Chemical Engineering, 1, 1-70.

[38] Akbar, N.S. (2015) Influence of Magnetic Field on Peristaltic Flow of a Casson Fluid in an Asymmetric Channel: Application in Crude Oil Refinement. Journal of Magnetism and Magnetic Materials, 378, 320-326. http://dx.doi.org/10.1016/j.jmmm.2014.11.056

[39] Nadeem, S. (2014) MHD Three Dimensional Boundary Layer Flow of Casson Nanofluid Past a Linearly Stretching Sheet with Convective Boundary Condition. IEEE Transactions on Nanotechnology, 13, 109-115. http://dx.doi.org/10.1109/TNANO.2013.2293735

[40] Hussain, T., Shehzad, S.A., Alsaedi, A., Hayat, T. and Ramzan, M. (2015) Flow of Casson Nanofluid with Viscous Dissipation and Convective Conditions: A Mathematical Model. Journal of Central South University, 22, 1132-1140. http://dx.doi.org/10.1007/s11771-015-2625-4 